\title{
Defending a Leopoldian Basis for Biodiversity: A Response to Newman, Varner, and Linquist
}

Published as Millstein, R.L. Defending a Leopoldian basis for biodiversity: a response to

Newman, Varner, and Linquist. Biol Philos 35, 12 (2020) doi:10.1007/s10539-019-9724-9

Roberta L. Millstein

Department of Philosophy

University of California, Davis

RLMillstein@,UCDavis.edu

\section{Introduction}

Two of the chapters of Defending Biodiversity are particularly relevant to Leopoldian defenses of biodiversity (that is, defenses of biodiversity inspired by the work of Aldo Leopold): Chapter 9, which discusses ecoholist defenses of biodiversity, and Chapter 10, which discusses J. Baird Calliott's interpretation of Leopold. In both chapters, Newman, Varner, and Linquist (hereafter NVL) cast doubt on whether such defenses, in their current form, have been successful. I was invited to participate in this symposium because my interpretations of Leopold and ecoholism differ from the canonical ones and because I've been explicitly connecting Leopold's work to contemporary ecology and conservation biology, the authors understandably not having been able to incorporate all defenses of biodiversity in their book, especially ones like mine that were being produced concurrently or subsequent to the time that their book was being written.

More specifically, NVL state: "From our critical discussion of Callicott on Leopold, we conclude that, philosophically speaking, Leopold's land ethic is weakly supported and, practically speaking, we think that $A$ Sand County Almanac itself provides precious little guidance" (2017, 302). What I will argue here is that the results of my ongoing project show: 1) There is a more accurate interpretation of Leopold that is not subject to the criticisms made by NVL, and 2) Leopold's body of work as a whole, including but not limited to the essay "The Land Ethic" in $A$ Sand County Almanac, provides quite a bit of useful guidance and perspective.

In what follows, I begin with a brief summary of some of my work on Leopold so far, with apologies that given space constraints the details of the arguments are contained within the papers themselves. This is intended to orient the reader who is more familiar with Callicott's interpretations. I then discuss NVL's Chapter 10 first followed by a discussion of their Chapter 9 , responding to their critiques. I then conclude.

\section{Millstein's reinterpretation of Leopold's Land Ethic}

In Millstein (2015), I argue against Callicott's (1987) claim that Leopold was committed to a view where the value of a land community is grounded in our extending moral sentiments to it. I show that there is scant textual evidence that Leopold was referencing Darwin's views about the evolution of ethics - and thus likewise scant evidence that Leopold was endorsing a Humean 
basis in moral sentiments for the land ethic. Moreover, I show that there is strong textual evidence for the view that Leopold's reference to the struggle for existence was to Chapter 3 of the Origin of Species, titled "Struggle for Existence," where Darwin discusses the interdependencies between species - a central theme of "The Land Ethic" - at great length.

In Millstein (2018a), I elaborate Leopold's conception of interdependence - the concept that lies at the heart of the land ethic - in line with contemporary ecology. I argue that Leopoldian interdependencies are between both biotic and abiotic components and encompass "positive" and "negative" ecological interactions (e.g., predator/prey, parasite/host, competitive interactions, mutualistic interactions). Indeed, what counts as "negative" and "positive" turns out to depend on context, time scale, and level of organization; for example, wolves predating on deer might have a "negative" effect on deer population sizes, but ultimately have a "positive" effect on the health of individual deer (because their population sizes are kept in check and they are less likely to run out of food to forage).

In Millstein (2018b), I debunked six myths about Aldo Leopold's land ethic. Here I'll mention three of the six debunked myths that are particularly relevant for the discussion here. One myth is that there there is a two-sentence "summary moral maxim" of the land ethic ("A thing is right when it tends to preserve the integrity, stability and beauty of the biotic community. It is wrong when it tends otherwise" Leopold, 1949, 224-225). These are only two sentences in a lifetime of work of a scientist/practitioner, not a philosopher, and they read much differently when considered in context of his life and work 1 (including the rest of "The Land Ethic") rather than in isolation. Another myth is that ecosystems are the only entities of value in the land ethic. There is good evidence that Leopold's land ethic values individual organisms as well as ecological wholes (in agreement with with Callicott's later work but in contrast to his early work). Finally, there is the myth that by stability, Leopold meant something like balance or dynamic equilibrium. As Freyfogle (2008) points out, too many authors simply assume that Leopold meant by stability what other ecologists of his time meant. Instead, as Julianne Warren (2016) persuasively demonstrates, by stability Leopold meant something closer to land health. In addition to debunking six myths, my paper makes the positive point that a correctly interpreted land ethic can be used to understand and justify successful restoration projects such as the Yolo Bypass in northern California's Sacramento Valley.

In Millstein (2018c), I argue that Leopold's concept of a land community (he uses the term biotic community interchangeably) is neither the community concept of early 20th century ecologists such as Clements nor the ecosystem concept of Tansley and subsequent ecologists. Rather, it contains elements of both concepts: interactions between species populations and matter/energy flows, respectively. I further show that Leopold's land community concept is consonant with much contemporary work in ecology. Finally, in response to worries that the land community isn't enough of an entity (thing, individual) to be morally considerable, I demonstrate how the boundaries of land communities can be delineated by discontinuities in the strengths of interactions between species populations and matter/energy flows.

In short, in these and other papers I argue for alternative interpretations to the ones that Callicott has defended, I elaborate and clarify the central concepts underlying the land ethic, and argue

${ }^{1}$ See Meine (2010). 
that Leopold's views are to a large extent consistent with contemporary ecology.

\section{Seven NVL criticisms of Callicott's interpretation of Leopold and responses}

In this section, I identify seven criticisms that NVL give of Callicott's interpretation of Leopold in Chapter 10 of their book and offer a response to each one, not on behalf of Callicott (who presumably would give different responses) but in light of my interpretation of Leopold, sketched in the previous section.

1. NVL criticism: Leopold's land ethic espouses extreme holism, suggesting that individual organisms (including humans) should always be sacrificed for the good of the land community. It is therefore draconian or fascist. Importantly, though, NVL acknowledge that this was a view of Leopold that Callicott endorsed early on and later retracted; as NVL recognize, Callicott no longer thinks this is the correct interpretation of Leopold.

Millstein response: On this point, I agree with Callicott's later work. Leopold speaks directly of the rights of individuals and talks of the land ethic as an "accretion" to (not a replacement of) previous ethical systems. He should not be understood as an extreme holist. The criticism of extreme holism is legitimate, but participants to this debate now agree that it is not a criticism of Leopold's view. We can therefore set it aside and move onto more important issues.

2. NVL criticism: Callicott commits the fallacy of "appeal to authority" by appealing to Darwin's views on the evolution of ethics, Hume's views on ethics, and communitarianism.

Millstein Response: As noted in the previous section, my interpretation doesn't rely on any of those traditions. I do appeal to Darwin as a scientist for interpretive purposes regarding interdependence but I also draw on contemporary scientific work (as well as philosophical argumentation) to defend the concept. Perhaps these can be seen as appeals to authority, but I believe they are no different to the citations to scientific work that NVL rely on throughout the course of their book.

3. NVL criticism: There are problems with Callicott's second-order principles for adjudicating conflicts between individuals and communities.

Millstein Response: I do not endorse Callicott's second-order principles, so the concerns that NVL raise here do not directly apply to my account. Nonetheless, it is undeniable that conflicts between what is best for individuals and what is best for communities as a whole are bound to arise and that adjudicating these conflicts will be difficult. This is work-in-progress for me, but here's what I've said in print so far (Millstein 2015).

Following Don Marietta (1999), we shouldn't ignore relevant sources of value by arbitrary fiat simply to achieve one clear answer. That is, there are good reasons to think that individuals have value based on characteristics such as their autonomy, their ability to feel pain, or even simply because they are alive, but that communities likewise have characteristics such as land health (more on this below) that are worthy of protection. Although the easiest route is to declare categorically the ways in which some values trump 
other values, the easiest route unjustifiably sacrifices some values for others.

Instead of thinking we can have an algorithm that will produce an answer to our complex questions, glossing over difficult tradeoffs, we might consider characterizing processes by which communities could make such decisions. The process might be similar to the one that Helen Longino (1990) describes for balancing competing values in science, notably including a diversity of perspectives. This would involve bringing different constituencies with their different values to the table, but with rules for their engagement such as uptake in response to legitimate criticism and equality of intellectual authority. This suggestion is Leopoldian in spirit, considering his frequent consultations with hunters, farmers, foresters, etc., in decisionmaking processes (as documented in Meine 2010).

4. NVL criticism: Callicott invokes group selection in a problematic way.

Millstein Response: My interpretation does not invoke group selection, since I am not claiming that Leopold thought that humans have evolved the tendency to extend moral sentiments to groups with which they are interdependent. ${ }^{2}$ Although Leopold thought that coming to respect land communities would typically involve emotions such as love, he strongly emphasized that this was also an intellectual process (requiring understanding of the science underlying the workings of a land community), and there is no reason to think that he saw these as evolved tendencies, as Callicott claims.

5. NVL criticism: NVL suggest (perhaps following Callicott) that Leopold adopts Clements's conception of community, a conception, they claim, that is tied to the understanding of a community as a superorganism. The problem is, they argue, that Clements's notion of community is outdated and has been discredited.

Millstein Response: It's worth noting that in recent work Callicott has developed an alternative conception of community (Callicott 2013), but in my view, it was not necessary for him to do so. As noted in the previous section, I have argued that although Leopold's conception of community shares some common elements with Clements's, it is distinctly his own, and that it is in fact in line with much contemporary work in ecology.

6. NVL criticism: If we update Leopold's community concept for the ecology of today, then we are limited to the local scale. At larger scales, interactions other than the common ecological ones (predation, parasitism, competition, etc.) matter most for species composition - at a medium scale, factors like speciation, migration, and extinction; at a continental scale, factors like geology and climate. This would have the unfortunate consequence that the land ethic would give short-shrift to larger-scale environmental concerns. ${ }^{3}$

Millstein response: This is an interesting criticism that is worthy of more response than I can give it here. But here is a sketch of one. What is essential for Leopold's land ethic is

2 That being said, I do not find group selection as problematic as NVL seem to; my point is only that it is not relevant for understanding or defending Leopold.

${ }^{3}$ Again, it's worth noting that Callicott's more recent work attempts to address the larger scale with a defense of a Leopoldian "earth ethic" (Callicott 2013). 
interdependence, not any particular manifestation of interdependence. Quoting Leopold: “All ethics so far evolved rest upon a single premise: that the individual is a member of a community of interdependent parts" (1949, 203).

Thus, it doesn't really matter for Leopold's account which interactions underlie interdependencies; they can be the traditional ecological interactions such as predator/prey, parasite/host, etc., but there is no reason they they have to be. Contemporary ecologists can and do speak of meta-communities, meta-meta-communities, etc. If it turns out that the interactions underlying these larger scale entities are, following NVL, factors like speciation, migration, and extinction, or factors like geology and climate, these interactions still serve to create interdependencies between individuals and between local land communities, and it is these interdependencies, I argue, that form the basis for our moral obligations.

Consider climate, for example. With human-caused climate change already well underway, it becomes even more true that the changes that humans make have effects on other local land communities across the globe. We can no longer separate climate from the activities of organisms - and arguably, they never could be separated, with our oxygen atmosphere resulting from the evolution of cyanobacteria as one such example. Geology is likewise intertwined with the activities of organisms; mountaintop removal mining is a clear example, organismic influence on soil is another. So, even though it might turn out to be the case that each of us is most strongly interdependent with our local communities, the larger-scale interdependencies are still substantial and are arguably morally relevant.

7. NVL criticism: Callicott misinterprets Hume.

Millstein Response: As mentioned above, my interpretation does not invoke Hume.

To summarize this section: The criticisms 1, 2, 4, 5 and 7 that NVL have made of Callicott's interpretation of Leopold in Chapter 10 do not challenge the interpretation of Leopold that I have defended. More work needs to be done to respond to criticisms 3 and 6, i.e., with respect to resolving conflicts between individuals and communities and to address how the land ethic handles scales larger than local land communities, but I believe that the tools to respond more fully in a Leopoldian vein are present.

\section{NVL's discussion of $A S C A$ 's "practical guidance" (Gh. 10) and responses}

After discussing Callicott's interpretation of Leopold, NVL turn to the practical guidance from Leopold himself in A Sand County Almanac (ASCA). They identify the following five claims as exhausting the practical guidance from Leopold himself:

1. We do not (and probably cannot) know enough to tinker precisely with ecosystems, designing them to get just the outcomes we want.

2. Regions vary in resilience, in the amount of human modification they can sustain without losing their long-term fecundity.

3. In all regions, the original, naturally evolved biota maintain long-term fecundity; 
introduced species may or may not.

4. In more fragile regions, a greater effort should be made to adopt agricultural and landscaping practices which mimic or approximate the original, naturally evolved ecosystems of the region.

5. In all regions, samples of the original biota (including all native species) should be preserved.

Regarding these five claims, NVL assert:

We think that statements \#\#2-5 above are good general advice with regard to the value of biodiversity and how to preserve it. But the advice reflects considerations of instrumental value of biodiversity in supporting ecosystem services, rather than an ecoholist appeal to the intrinsic value of species and ecosystems. And as far as practical guidance goes, statements \#\#2-5 are of the 'be sure to pay heed to this in deciding on a general conservation strategy' variety, rather than principles that give much substantive, practical guidance to policy makers (2017, 352; emphasis added).

I basically agree that these five statements represent points that Leopold urged, although I might quibble with some of the wording; for example, as noted already, "ecosystem" is not an entirely accurate representation of what Leopold meant by land community, and "long-term fecundity," a term usually used to refer to the number of offspring produced by individual organisms, seems an odd choice to express what Leopold called stability or land health. Since Leopold was such an individualistic thinker, it's probably best to use his own terms rather than contemporary ones, and I think this is in general a good practice when discussing historical figures. Nonetheless, again, I do think that the five claims that NVL identified are more or less ones that Leopold did indeed endorse.

However, I think there is far more practical guidance to be found in his work and more to be said about each statement. As noted in Section 2, I've previously argued that Leopold's ideas can provide a defensible and fruitful ethical basis for restoration projects. But most relevantly for the topic of biodiversity is the question of stability or land health. By land health, Leopold meant the ability of the land to cycle nutrients efficiently and continuously over long periods of time (Warren 2016). This, Leopold hypothesized, requires long and diverse food chains, so that, e.g., nutrients would be "bound up" in organisms and not get lost to soil erosion ([1942] 1999]. This would permit the land to continue to sustain life over time, making it capable of self-renewal.

Thus, preserving species - one sense of preserving biodiversity - is key to preserving land health because it is key to preserving the long and diverse food chains (representing interdependencies between species) required for land health. But does this merely reflect "considerations of instrumental value of biodiversity in supporting ecosystem services", as NVL suggest that Leopold's advice does? Not if land communities have intrinsic value ${ }^{4}$ and not if land health is the

\footnotetext{
${ }^{4}$ In what follows, "intrinsic value" can be understood in a minimal way, e.g., "things valued for their own sake apart from their usefulness to us" or in a more robust way, e.g. "things that have value even in the absence of any valuers." NVL make a similar distinction in their book; my claim here is only that the
} 
characteristic of land communities that we ought to try to preserve.

So, let us turn (briefly) to the topic of intrinsic value, which NVL discuss in Chapter 9.

\section{Intrinsic value arguments for ecoholism}

In Chapter 9, NVL accuse many proponents of intrinsic value of ecological wholes of committing various fallacies (e.g., the naturalistic fallacy) or of making other problematic arguments. There is probably more to be said about each of these and whether Leopold makes any of these purported mistakes, but for reasons of space, I'll just focus on what NVL take to be a reasonable sort of argument: the method of reflective equilibrium/coherentism (Ch. 7): "In the method of reflective equilibrium, one repeatedly examines the consistency of one's beliefs, making adjustments at one or both levels, until they are all in harmony with each other" (2017, 219). An example might be Singer's argument in defense of sentientism, which appeals to common beliefs about interests and the ethical relevance of the ability to feel pain to argue that sentient animals have interests, too, on pain of inconsistency.

To be clear, NVL don't fully endorse the method of reflective equilibrium because it cannot tell us whether an ethical theory is true, only that the proposed ethical theory is part of a coherent set of beliefs. They nonetheless choose to deploy it in the book because 1) almost everyone in fact relies on it, 2) it is a reasonable approach to justifying beliefs (again, although not "proving" them to be true) and expresses a commitment to rationality in ethics, and 3) there are "extensive limitations on both appeals to self-evidence and appeals to logical requirements in establishing the truth of moral judgements, principles, and theories" (2017, 221-223). I agree that the method of reflective equilibrium is a reasonable approach to justifying beliefs, and so, in the absence of anything better (and in the absence of any other approach endorsed by NVL), I will use it here.

It seems to me that we can understand Leopold's argument in "The Land Ethic" as using the method of reflective equilibrium ${ }^{5}$ and thus needn't attribute to him any of the mistakes in reasoning that NVL are concerned about. Here I reconstruct: ${ }^{6}$

1. Given interdependence between humans, we accept the value of human communities and accept limitations on our actions (rules of conduct) to benefit and protect those communities; our ethical theories capture these rules of conduct.

2. Ecology shows us that we are not just interdependent with other humans, but also interdependent with other species and with abiotic components such as soil and water;

arguments I make do not depend on one reading vs. another. As for Leopold, it's clear that he at least means to endorse the minimal sense; whether his reference to "value in the philosophical sense" (1949, 223) commits him to the more robust sense is difficult to determine.

${ }^{5}$ Although I think Leopold's argument can reasonably be understood as deploying the method of reflective equilibrium, as explained below, not much hangs on that claim. If the reader prefers, it can simply be understood as an appeal to consistency in our ethical beliefs.

${ }^{6}$ I hope that even without the textual evidence, this argument seems familiar to readers of "The Land Ethic." 
together, we form land communities.

3. Therefore [consistency demands], we ought to recognize that our land communities have value and that we ought to accept an ethical theory that benefits and protects them - a land ethic.

The main change to our ethical belief system would thus be to include land communities as morally considerable entities, although other beliefs would have to change as well. For example, Leopold famously states that "a land ethic changes the role of Homo sapiens from conqueror of the land-community to plain member and citizen of it, implying "respect for [one's] fellow-members, and also respect for the community as such" $(1949,204)$. But note also that Leopold says that the land ethic is a "product of social evolution" and that "evolution never stops" (1949, 225). Perhaps it's not too much of a stretch to read this as saying that further adjustments to one's beliefs in light of consistency may be required, something that would probably have been all too evident to someone who began his career believing in predator control and yet at the end of his life mourned the death of a wolf he had killed many years before. ${ }^{7}$

Here it might be objected that neither I nor Leopold has shown that human communities have intrinsic value, and if they don't, then the reflective equilibrium argument (however legitimate) cannot support the intrinsic value of land communities. This requires more argumentation than I can give here, but I think it is at least not implausible to think (we think) that human communities have intrinsic value, given the sacrifices that many human individuals make for the good of their communities, even at the end of their lives when they cannot hope to benefit themselves. (Soldiers who are willing to die for their countries come to mind). If this is right, then the reflective equilibrium argument for the intrinsic value of land communities holds. As NVL's arguments suggest, this would not prove the truth of the conclusion of the argument, but it could serve to justify it and show that the land ethic is part of a coherent set of ethical beliefs, rather than merely being an instrumental set of guidelines.

Another objection to the reconstructed argument might be that human communities and land communities are not sufficiently analogous to one another to make the consistency claim - that the interdependencies between humans, based on our relationships within families and within societies, are very different from interdependencies among biotic and abiotic entities more generally. It is true that many human interdependencies are social - but then, depending on species, some animal interdependencies are social, too. Let's take a closer look at interdependencies for a moment.

Glearly, many ecological interactions have to do with survival: competitive interactions, predator/prey interactions, parasite/host interactions, mutualistic interactions. But, at the risk of being reductionistic, many human interactions do, too. The most obvious example is a parental care for an offspring, but the truth is that we humans all depend on each other in a variety of ways, whether it is providing food, shelter, transportation - all of which are analogous to ecological interactions. Even the "negative" interactions, which I argue give rise to interdependencies too (Millstein 2018a, mentioned above), are likewise present in human societies and likewise give rise to interdependencies; to give one example, we have an economic

7 See the essay "Thinking Like a Mountain" in ASCA. 
system that is based on competition, but other areas are arguably based on competition as well (education, government, sports). And, like ecological interactions, our "negative" actions can have positive effects in some contexts or on other individuals, with interdependencies best thought of as a web rather than solely in terms of pair-wise interactions. Of course, we are interdependent in psychological ways, too, and these may not be analogous to ecological interdependencies. Like all analogies, the two things being compared are not entirely similar. All Leopold needs for the argument to go through is that human interdependencies and ecological interdependencies are are sufficiently similar and that that interdependencies are relevant to our ethical rules.

In the rest of Chapter 9, NVL question whether 1) ecosystems have evolved interests, 2) ecosystems are real physical entities, and 3) ecosystem health can be defined. With respect to \#1, it's not clear why a characteristic needs to be evolved in order to counts as an interest; in sympathy with Taylor (1981), all that seems required is that the entity in question can be benefitted or harmed (which can be answered in the affirmative if we can respond affirmatively to question \#3 about land health). With respect to \#2 and \#3, I have already sketched how land communities are real, physical entities (bounded by discontinuities in interactions and matter/energy flows) and how land health can be defined (the ability of the land to cycle nutrients efficiently and continuously over long periods of time). So, none of these questions are barriers to land communities ("ecosystems") having intrinsic value.

In short, Leopold's work offers both the argumentative tools and the conceptual tools for thinking that we can make sense of land communities as having intrinsic value. Thus, the ground is cleared for the Leopoldian claim that preserving biodiversity is key to preserving land health for the sake of land communities themselves, apart from any benefit to us.

\section{Conclusion}

Although my points here are surely in need of further elaboration, I have given a sketch of the case for why the concerns that Newman, Varner, and Linquist raise for a Leopoldian defense of biodiversity do not hold - once we have in hand a more textually accurate interpretation of Leopold. On this revised interpretation that I have given, Leopold's land ethic is defended by the method of reflective equilibrium, showing us that the land communities that we are interdependent with have intrinsic value, necessitating preserving their (land) health, which in turn necessitates preserving biodiversity. 


\section{References}

Callicott, J. Baird. 1987. "The Conceptual Foundations of the Land Ethic." In Companion to a Sand County Almanac, edited by J. Baird Callicott, 186-217. Madison, WI: University of Wisconsin Press.

- 2013. Thinking Like a Planet: The Land Ethic and the Earth Ethic. Oxford: Oxford University Press.

Freyfogle, Eric T. 2008. "Land Ethic." In Encyclopedia of Environmental Ethics and Philosophy, edited by J. Baird Callicott and Robert Frodeman. Macmillan Reference USA.

Leopold, Aldo. 1949. A Sand County Almanac and Sketches Here and There. New York: Oxford University Press.

— - [1942] 1999. "Biotic Land Use." In Aldo Leopold: For the Health of the Land: Previously Unpublished Essays and Other Writings, edited by J. Baird Callicott and Eric T. Freyfogle, 198-207. Washington, D.C.: Island Press.

Longino, Helen. 1990. Science as Social Knowledge. Princeton: Princeton University Press.

Marietta Jr., Don E. 1999. "Environmental Holism and Individuals." In Environmental Ethics: Concepts, Policies, Theories, edited by Joseph DesJardins, 238-246. Mountain View: Mayfield.

Meine, Curt. 2010. Aldo Leopold: His Life and Work. Madison, WI: University of Wisconsin Press.

Millstein, Roberta L. 2015. "Re-Examining the Darwinian Basis for Aldo Leopold's Land Ethic." Ethics, Policy E Environment 18:301-317.

_ 2018a. "Understanding Leopold's Concept of 'Interdependence' for Environmental Ethics and Conservation Biology." Philosophy of Science 85:1127-1 139.

_ 2018b. "Debunking Myths About Aldo Leopold's Land Ethic." Biological Conservation 217:391-396.

- 2018c. "Is Aldo Leopold's 'Land Community' an Individual?" In Individuation, Process, and Scientific Practices, edited by O. Bueno, R. Chen and M. B. Fagan, 279-302. Oxford: Oxford University Press.

Newman, Jonathan A., Gary Varner, and Stefan Linquist. 2017. Defending Biodiversity: Environmental Science and Ethics. Cambridge: Cambridge University Press.

Taylor, Paul. 1981. "The Ethics of Respect for Nature." Environmental Ethics 3:197-218.

Warren, Julianne Lutz. 2016. Aldo Leopold's Odyssey: Rediscovering the Author of a Sand County Almanac. 10th Anniversary Edition ed: Island Press. 